\title{
Characterization of the effect of brick-powder application in lime-based plasters
}

\author{
D. Koňáková ${ }^{1}$, E. Vejmelková ${ }^{1}$, M. Č́chová ${ }^{1}$, P. Reiterman ${ }^{2}$, \\ M. Keppert ${ }^{1} \&$ R. Černý ${ }^{1}$ \\ ${ }^{1}$ Department of Materials Engineering and Chemistry, Faculty of Civil \\ Engineering, Czech Technical University in Prague, Czech Republic \\ ${ }^{2}$ Experimental Centre, Faculty of Civil Engineering, \\ Czech Technical University in Prague, Czech Republic
}

\begin{abstract}
Brick powder is applied in lime plasters as both supplementary cementitious material replacing a part of lime binder and aggregate replacing a part of siliceous sand. The characterization of its effect on the properties of modified plasters is performed using the measurement of a wide set of parameters including bulk density, matrix density, open porosity, compressive strength, bending strength, water absorption coefficient, water vapour diffusion resistance factor, thermal conductivity and specific heat capacity. Experimental results show a positive influence of the brick powder application on the mechanical properties while the other parameters remain satisfactory.

Keywords: lime, brick powder, basic physical properties, mechanical strength, hygric parameters, thermal characteristics.
\end{abstract}

\section{Introduction}

Utilization of classic building materials combined with the recent trends of development in the civil engineering branch brings new perspective on materials engineering, as well as new application possibilities. Ceramics and burnt clay products belong among the classic materials with great permanent general popularity. Technological process of ceramics production passed through widespread development during thousands year of its usage. Gradually, modern burned ceramic blocks have been developed from handmade green bricks. 
Similarly to many other materials, ceramics can also be considered as valuable waste products, as obtained either during their production process or after their service life. It was proved by Pereira de Oliveira et al. [1] that ground ceramics shows pozzolanic activity. Pozzolanicity of some bricks and clays was reported also by Baronio and Binda [2]. Most of the researches were in their studies focused on the utilization of the waste ceramics in concrete production, either as alternative aggregate or as supplementary cementitious material (SCM). The utilization of waste ceramics as an alternative aggregate in concrete production was the matter of the study performed by Poon and Chan [3]. Similar attempts were done by Debieb and Kenai [4]. On the other hand, Pacheco-Torgal and Jalali [5] studied mechanical and durability properties of ceramics used as SCM in concrete. Heidari and Tavakoli [6] investigated mechanical properties of ground ceramic powder concrete incorporating nano- $\mathrm{SiO}_{2}$ particles. Reiterman et al. [7] dealt with concrete containing fine ceramic powder; they investigated its basic physical, mechanical and hygric properties.

Another group of researchers focused their work on mortars containing ceramic materials, for example Gonçalves et al. [8] who studied cement mortars modified with metakaolin or ground brick. Yan et al. [9] focused their research on utilization of waste ceramics as ecological building mortar component. Strength and chemical resistance of these materials were the matter of the study performed by O'Farrell et al. [10].

Just few attempts were paid to research of plasters with ceramics, although plasters containing ceramic admixture can bring improvement of building claddings. The interaction between background and plaster should be the best as possible, and materials with similar bases (as plaster containing ceramics and brick wall) are predicted to interact very well. Ugurlu and Boke [11] dealt with bricklime plasters and their relevance to climatic conditions of historic buildings. Improvement of historical plasters containing brick or tile powder by ground granulated blast-furnace slag was the matter of the study performed by Isikdag and Topcu [12]. In their other study they tried to utilize fly ash as alternative aggregate in ceramic based lime plasters [13].

In this article lime plasters with admixture of ceramic material were studied. The utilized ceramics is waste material originating in grinding process of brick production, and its employment may not only lead to the improvement of physical properties; it may also have economic and ecological advantages. Plasters with different amount of waste ceramics in the form of both binder and aggregate partial replacement are examined and the applicability of ceramic admixture is evaluated from the point of view of basic physical, mechanical, hygric and thermal properties of studied plasters.

\section{Material composition}

Specific composition of studied plasters is presented in Table 1. Designed materials belong among the lime plasters. Primary binder is lime CL 90-S produced by Vápenka Čertovy schody, a.s.; this material is almost pure lime, with $99.33 \%$ of $\mathrm{CaO}$. As the main aggregate, three gradings of silica sand with $98.5 \%$ 
content of $\mathrm{SiO}_{2}$ are utilized. Potable water is used, and its amount is set by utilization of the fluiding experiment with the requirement of 160/160 mm.

Table 1: Composition of studied plasters.

\begin{tabular}{|c|c|c|c|c|c|c|}
\hline & \multirow[b]{2}{*}{$\begin{array}{c}\text { Lime } \\
(\mathrm{kg})\end{array}$} & \multirow{2}{*}{$\begin{array}{c}\text { Ceramic } \\
\text { powder } \\
(\mathrm{kg})\end{array}$} & \multicolumn{3}{|c|}{ Sand (kg) } & \multirow[b]{2}{*}{$\begin{array}{c}\text { Water } \\
\text { (L) }\end{array}$} \\
\hline & & & $\begin{array}{c}0.3-0.8 \\
\mathrm{~mm}\end{array}$ & $\begin{array}{c}0.6-1.2 \\
\mathrm{~mm}\end{array}$ & $\begin{array}{c}1.0-4.0 \\
\mathrm{~mm}\end{array}$ & \\
\hline PR & 3.75 & 0.00 & 3.75 & 3.75 & 3.75 & 3.7 \\
\hline P1 & 3.56 & 0.75 & 3.56 & 3.56 & 3.56 & 3.9 \\
\hline $\mathrm{P} 2$ & 3.19 & 2.25 & 3.19 & 3.19 & 3.19 & 4.4 \\
\hline P3 & 2.81 & 3.75 & 2.81 & 2.81 & 2.81 & 4.4 \\
\hline
\end{tabular}

The matter of this study is to determine the influence of the brick powder as a potential component of lime plasters. This waste material originates in the grinding process of a new kind of thermal insulating bricks and it has form of finely ground ceramics. Chemical composition of this secondary raw material is presented in Table 2. In this work different approach than in our previous studies is chosen. An effect of the ceramic powder as supplementary lime material [14] as well as its utilization as alternative aggregate [15] was already investigated. Now we study the effect of the ceramic powder utilized as both lime and aggregate replacement. Four mixtures with different amount of ceramic powder were designed where 10, 30 and $50 \%$ of total mass of powder materials (lime and sand) were replaced by the waste ceramic. For the sake of comparison the reference material, pure lime plaster, was also prepared and examined.

Table 2: Chemical composition of brick powder (in mass \%).

\begin{tabular}{|l|c|c|}
\hline & Total composition & Amorphous phase \\
\hline $\mathrm{SiO}_{2}$ & 51.3 & 24.4 \\
\hline $\mathrm{Al}_{2} \mathrm{O}_{3}$ & 20.0 & 33.7 \\
\hline $\mathrm{Fe}_{2} \mathrm{O}_{3}$ & 6.0 & 7.1 \\
\hline $\mathrm{CaO}$ & 11.5 & 19.0 \\
\hline $\mathrm{MgO}$ & 4.5 & 7.9 \\
\hline $\mathrm{K}_{2} \mathrm{O}$ & 3.2 & 2.3 \\
\hline $\mathrm{Na}_{2} \mathrm{O}$ & 1.3 & 1.1 \\
\hline $\mathrm{TiO}_{2}$ & 0.8 & 1.5 \\
\hline $\mathrm{SO}_{3}$ & 1.0 & 1.2 \\
\hline
\end{tabular}

\section{Experimental methods}

\subsection{Basic physical properties}

The bulk density, matrix density and open porosity were measured using the vacuum water saturation method [16]. This method is based on weighing samples in different states. Three samples of each type of composites with dimensions of 
$40 \times 40 \times 40 \mathrm{~mm}$ were used for this measurement. The first measured state was the dried one. To remove physically bounded water, the samples were put into a drying box kept at the temperature of $105^{\circ} \mathrm{C}$. The second state was the saturated one. The samples were put into a desiccator with boiled distilled water and air was evacuated with a vacuum pump. After removing the samples from the desiccator, their mass in the saturated state was determined. Finally, the value necessary for calculating the basic physical properties is the mass of saturated samples under water, the so called Archimedes mass.

Characterization of a pore structure was determined by the mercury intrusion porosimetry. This method is based on the determination of the external pressure needed to force the mercury into a pore against the opposing force of the liquid's surface tension. The pore size is then calculated from the measured pressure using Washburn's equation. The experiments were carried out using instruments PASCAL 140 and 440 (Thermo Scientific). The range of an applied pressure corresponds to the pore radius from $10 \mathrm{~nm}$ to $100 \mu \mathrm{m}$.

\subsection{Mechanical properties}

Primary mechanical properties as compressive strength and bending strength were measured. A measurement of bending strength was performed using the loading device MTS 100 according to standard [17]. Six samples with dimensions of $160 \times 40 \times 40 \mathrm{~mm}$ were prepared. An arrangement of the experiment was the classical three-point bending with $100 \mathrm{~mm}$ length span. Loading was performed up to the failure, and the ultimate force was noted. By means of calculated maximum bending moment and known section modulus the bending strength is evaluated according to the well-known equation.

For determination of compressive strength special loading device EU40 was employed. The experiment was also performed according to standard [17]. The samples from the measurement of bending strengths were used, so compressive strength was determined twelve times. In the actual experiment samples were put between two steel pressure plates with dimensions of $40 \times 40 \mathrm{~mm}$. Great emphasis was given to the centering of the arrangement, since only simple compression should act. Acting force was noted as in the case of bending strength, and by means of it and known loading area compressive strength was calculated.

\subsection{Hygric properties}

The liquid water transport was characterized by the water absorption coefficient. Three specimens with dimension of $50 \times 50 \times 50 \mathrm{~mm}$ were water- and vapourproof insulated on four lateral sides and the face side was immersed 1-2 mm in water. A constant water level in the tank was achieved by a Mariotte bottle with two capillary tubes [18]. One of them, with an inside diameter $2 \mathrm{~mm}$, was ducked under the water level. The second one, with an inside diameter $5 \mathrm{~mm}$, was above water level. The automatic balance allowed recording the increase of the mass. The water absorption coefficient was calculated from the sorptivity plot [18] which was set up from measured data. The apparent moisture diffusivity was 
calculated from water absorption coefficient using the procedure described in [19], as an approximation to the real moisture diffusivity which depends on moisture content.

The cup method was employed in the measurements of water vapour transport parameters [16]. For this measurement three cylindrical samples (with $120 \mathrm{~mm}$ diameter and $20 \mathrm{~mm}$ height) were, similarly to the liquid transport experiment, water- and vapour-proof insulated on four lateral sides and then the cups were prepared. In the dry-cup method sealed cups containing silica gel were placed in a controlled climatic chamber with $50 \%$ relative humidity and weighed periodically. For the wet-cup method the sealed cups contained water. The measurements were carried out at $25^{\circ} \mathrm{C}$ over a period of five weeks. The steady state values of the mass gain or mass loss determined by linear regression for the last five readings were used for the determination of water vapour transport parameters which were calculated using the procedure described in [16].

\subsection{Thermal properties}

The last group of measured characteristics was thermal properties. Using the device ISOMET 2104 [20], the thermal conductivity and specific heat capacity were measured. This commercial device applies a dynamic measurement method so that time of measurement reduces to dozens of minutes. The measurement process is based on an analysis of a temperature response of an analyzed material to heat flow impulses. The heat flow is induced in a resistor of a probe by a distributed electric power. The temperature is recorded and evaluated from the polynomial regression. The thermal conductivity was determined in dependence on the moisture content. Three samples with dimensions of $70 \times 70 \times 70 \mathrm{~mm}$ were employed for the measurement of thermal properties.

\section{Experimental results}

\subsection{Basic physical properties}

Results of the water vacuum saturation measurement are summarized in Table 3. It is obvious that by utilization of the ceramic powder as both lime and aggregate replacement matrix density increases. In the case of plaster with $50 \%$ of the waste material the growth is higher than $11 \%$. Regarding measured values of bulk density, they show a decreasing trend. The difference between the reference material and plaster with $50 \%$ replacement is almost $6 \%$. Also open porosity shows different values. It increases with increasing amount of the ceramic powder. In comparison with the reference material, the special plaster with $50 \%$ of the ceramic powder reaches by more than $12 \%$ higher value of open porosity. For a detailed description of pore structure changes pore size distribution curves are presented in Figure 1 where the growth of micropores ranging from $0.1 \mu \mathrm{m}$ to $1 \mu \mathrm{m}$ caused by ceramic admixture can be seen. This fact has a substantial influence on the other studied transport characteristics. 
Table 3: Basic physical properties.

\begin{tabular}{|c|c|c|c|}
\hline & $\begin{array}{c}\text { Bulk density } \\
\left(\mathrm{kg} \mathrm{m}^{-3}\right)\end{array}$ & $\begin{array}{c}\text { Matrix density } \\
\left(\mathrm{kg} \mathrm{m}^{-3}\right)\end{array}$ & $\begin{array}{c}\text { Open porosity } \\
(\%)\end{array}$ \\
\hline PR & 1699 & 2328 & 27.0 \\
\hline P1 & 1675 & 2557 & 34.5 \\
\hline P2 & 1618 & 2599 & 37.4 \\
\hline P3 & 1598 & 2622 & 39.1 \\
\hline
\end{tabular}

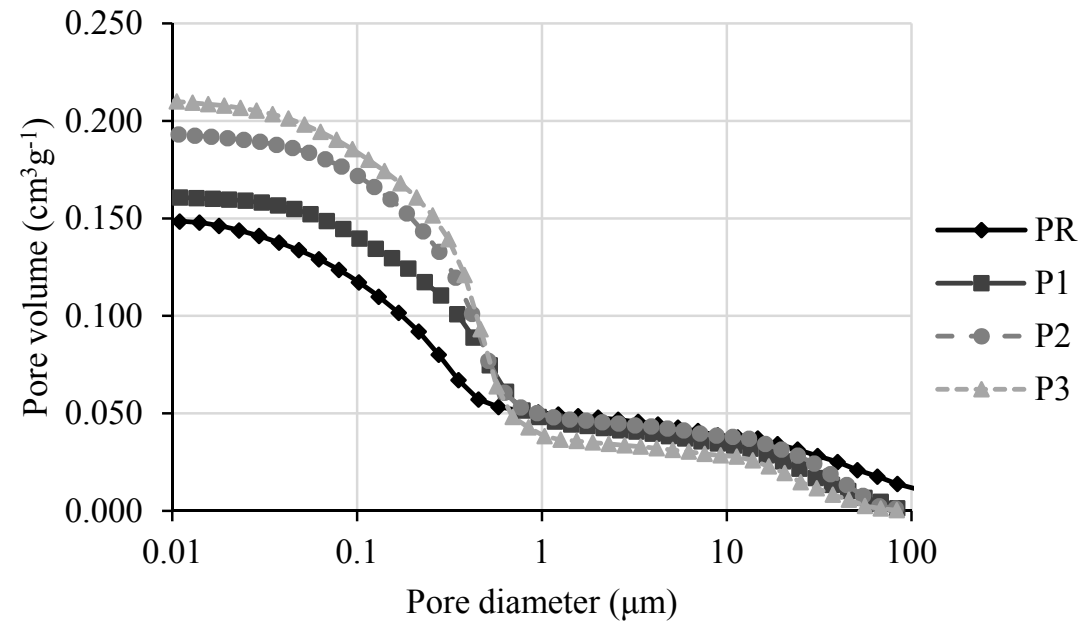

Figure 1: $\quad$ Pore size distribution curve.

\subsection{Mechanical properties}

Measured compressive strengths and bending strengths are shown it Table 4. By replacing $50 \%$ of lime and aggregate compressive strength grows by more than $82 \%$, while bending strength goes up by almost $46 \%$. Although open porosity (Table 3 ) of studied plasters grows with increasing amount of ceramic admixture, positive effect of the ceramics on the mechanical properties is indisputable. The reason for the improvement is probably pozzolanic reaction of ceramic powder, which leads to changes of material structure as well as its pore size distribution.

Table 4: Mechanical properties.

\begin{tabular}{|c|c|c|}
\hline & Compressive strength (MPa) & Bending strength (MPa) \\
\hline PR & 0.62 & 0.25 \\
\hline P1 & 1.33 & 0.36 \\
\hline P2 & 1.90 & 0.42 \\
\hline P3 & 3.50 & 0.46 \\
\hline
\end{tabular}




\subsection{Hygric properties}

The first group of measured characteristics describes water vapour transport. Results achieved by employing cup methods are presented in Table 5 (dry cup arrangement) and Table 6 (wet cup arrangement). Regarding the influence of waste ceramic powder, it has increasing effect on water vapour transport ability. Water vapour diffusion resistance factor of special plaster with $50 \%$ of ceramic powder is by $32 \%$ lower in the case of dry cup measurement that water vapour diffusion resistance factor of the reference material. In the case of wet cup measurement, the difference is about $6 \%$. As it was mentioned above pore structure has the main influence on transport properties and the achieved results are in accordance with different pore structure of studied plasters (Table 3 and Figure 1). Both arrangements show different results; values of water vapour diffusion resistance factor obtained by dry-cup method are always higher than the values from wet cup method. It is a well-known phenomenon, which was observed also in the case of other materials. It is caused probably by a partial transport of capillary condensed water at higher relative humidity [21].

Table 5: Water vapour transport properties - dry cup arrangement.

\begin{tabular}{|c|c|c|c|}
\hline & $\begin{array}{c}\text { Water vapour } \\
\text { diffusion } \\
\text { permeability (s) }\end{array}$ & $\begin{array}{c}\text { Water vapour } \\
\text { diffusion } \\
\text { coefficient }\left(\mathrm{m}^{2} \mathrm{~s}^{-1}\right)\end{array}$ & $\begin{array}{c}\text { Water vapour } \\
\text { diffusion resistance } \\
\text { factor }(-)\end{array}$ \\
\hline PR & $4.55 \mathrm{E}-12$ & $6.25 \mathrm{E}-07$ & 37.2 \\
\hline P1 & $4.82 \mathrm{E}-12$ & $6.63 \mathrm{E}-07$ & 34.8 \\
\hline P2 & $4.97 \mathrm{E}-12$ & $6.83 \mathrm{E}-07$ & 33.8 \\
\hline P3 & $6.66 \mathrm{E}-12$ & $9.15 \mathrm{E}-07$ & 25.3 \\
\hline
\end{tabular}

Table 6: Water vapour transport properties - wet cup arrangement.

\begin{tabular}{|c|c|c|c|}
\hline & $\begin{array}{c}\text { Water vapour } \\
\text { diffusion } \\
\text { permeability }(\mathrm{s})\end{array}$ & $\begin{array}{c}\text { Water vapour } \\
\text { diffusion } \\
\text { coefficient }\left(\mathrm{m}^{2} \mathrm{~s}^{-1}\right)\end{array}$ & $\begin{array}{c}\text { Water vapour } \\
\text { diffusion resistance } \\
\text { factor }(-)\end{array}$ \\
\hline PR & $2.41 \mathrm{E}-11$ & $3.31 \mathrm{E}-06$ & 7.01 \\
\hline P1 & $2.49 \mathrm{E}-11$ & $3.42 \mathrm{E}-06$ & 6.74 \\
\hline P2 & $2.53 \mathrm{E}-11$ & $3.48 \mathrm{E}-06$ & 6.61 \\
\hline P3 & $2.64 \mathrm{E}-11$ & $3.63 \mathrm{E}-06$ & 6.57 \\
\hline
\end{tabular}

The second group of measured hygric characteristic deals with water liquid transport. The values of water absorption coefficient as well as apparent moisture diffusivity are summarized in Table 7 . Although open porosity of studied plasters (Table 3) grows considerably with growing amount of ceramic admixture in studied plasters water absorption coefficient shows a slight decrease. The difference between values achieved for the reference material and the plaster with $50 \%$ of ceramic powder is less than $6 \%$. In the case of liquid water transport the 
main influencing characteristic is also pore structure (as well as in the case of water vapour transport), but the amount of pores ranging from $1 \mu \mathrm{m}$ to $1000 \mu \mathrm{m}$ has the greatest importance. It can be seen on the pore size distribution curves (Figure 1) that in that range the amount of pores decreases a little with increasing amount of ceramic powder. The same behaviour, a slight decrease, can also be observed in the case of liquid water transport parameters.

Table 7: Liquid water transport parameters.

\begin{tabular}{|c|c|c|}
\hline & $\begin{array}{c}\text { Water absorption coefficient } \\
\left(\mathrm{kg} \mathrm{m}^{-2} \mathrm{~s}^{-1 / 2}\right)\end{array}$ & $\begin{array}{c}\text { Apparent moisture } \\
\text { diffusivity }\left(\mathrm{m}^{2} \mathrm{~s}^{-1}\right)\end{array}$ \\
\hline PR & 0.235 & $7.65 \mathrm{E}-07$ \\
\hline P1 & 0.233 & $4.93 \mathrm{E}-07$ \\
\hline P2 & 0.232 & $3.91 \mathrm{E}-07$ \\
\hline P3 & 0.221 & $3.10 \mathrm{E}-07$ \\
\hline
\end{tabular}

\subsection{Thermal properties}

Thermal conductivity depending on moisture content (Figure 2) decreases with increasing amount of the waste material; it corresponds with increasing porosity (Table 3). In the case of material with $50 \%$ replacement the fall was by almost $44 \%$ in dry state. From measured results it can be concluded that the utilization of the ceramic powder has a positive effect on the thermal insulating abilities of the designed plasters. It is obvious that as the moisture content grows the thermal conductivity increases. This tendency is a common phenomenon caused by the different values of thermal conductivity of water and air. The thermal conductivity grows by about $62 \%$ on average thanks to increasing moisture content.

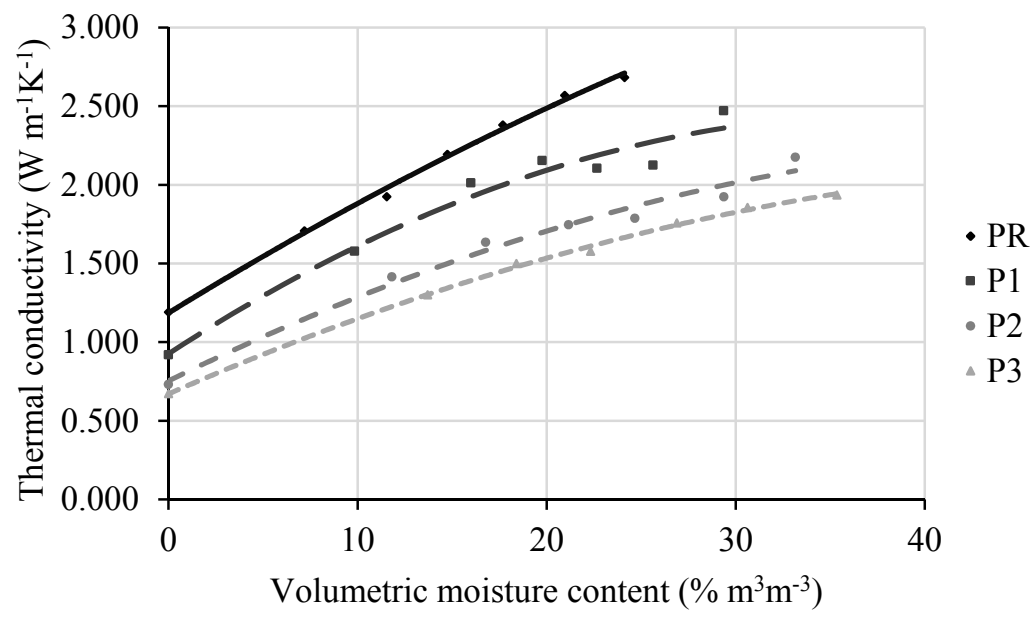

Figure 2: Thermal conductivity. 
In Figure 3 the dependency of specific heat capacity on volumetric moisture content is presented. Regarding the effect of ceramic replacement, with increasing amount of waste admixture values of specific heat capacity grow. For the plaster with the highest replacement the increase was by about $32 \%$. As in the case of thermal conductivity also specific heat capacity shows a growing trend with increasing moisture content. The reason for this behaviour is also the same like in the previous case; specific heat capacity of water and air vary widely. Specific heat capacities in dry state and fully saturated state differ by about $75 \%$ on average.

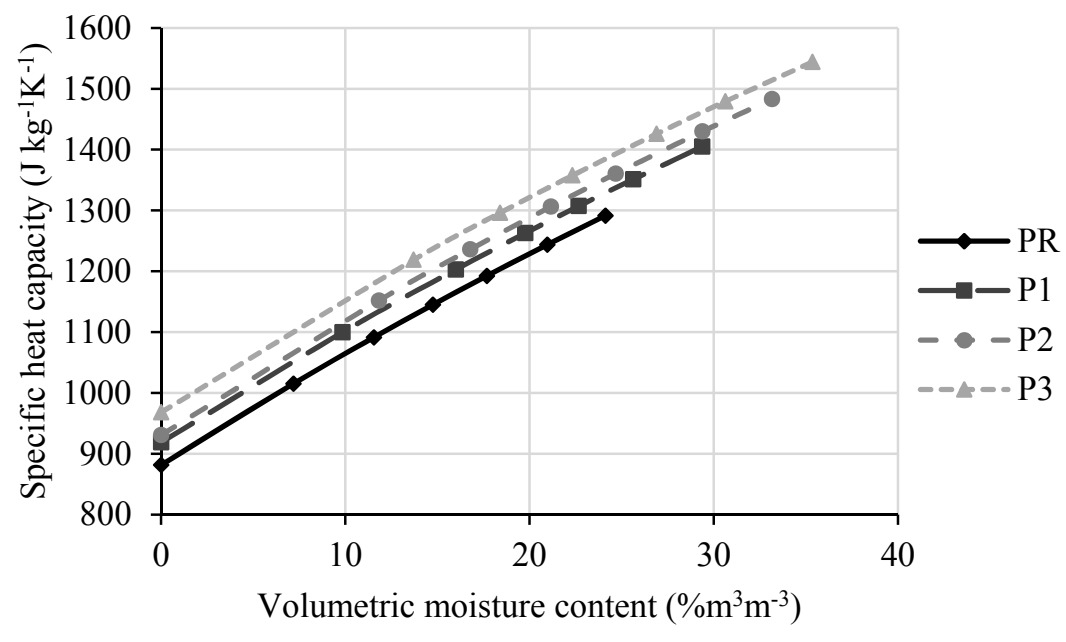

Figure 3: Specific heat capacity.

\section{Conclusions}

The matter of our study was to investigate the possibilities of utilization of waste ceramic powder as a potential admixture to lime plasters. This secondary raw material is a by-product of bricks manufacturing. During the grinding process of ceramic brick, the ceramic powder arises. Its utilization meets modern requirements for new materials as for example a price reduction, employment of waste material, and improvement of classic materials. Three mixtures with different amount of ceramic powder were investigated. Amount of utilized secondary raw material was set as $10 \%, 30 \%$, and $50 \%$ of powder component of lime plasters, thus both binder and aggregate was replaced. Achieved results can be summarized as follows.

Bulk density decreases with increasing amount of the ceramic admixture, in the case of maximum replacement by about $6 \%$. Matrix density goes up by about $12 \%$, and open porosity increases as well. Pore structure changes resulting from ceramic replacement can be characterized by an increasing amount of micropores with the diameter up to $1 \mu \mathrm{m}$. 
The utilization of ceramic powder has undoubtedly a positive effect on mechanical strengths (compressive strength as well as bending strength). Both characteristics show considerable growth; $50 \%$ ceramic powder replacement leads to $82 \%$ increase of compressive strength and $46 \%$ increase of bending strength. It is caused by pozzolanic reaction of the waste material and lime which leads to the changes in material structure.

Water transport characteristics were divided into two parts according to the physical phase of water. Thanks to the replacement of binder and aggregate by the ceramic powder water vapour transport abilities increase, because of the growth of micropore amount, while thanks to the capillary pores fall the liquid water transport characteristics show a slight decrease.

Also thermal properties were affected by utilization of the waste material as plaster admixture. Thermal conductivity was decreased, while specific heat capacity was increased. From achieved results it can be deduced that ceramic powder leads to an improvement of thermal insulating ability of lime plasters.

The experimental results summarized above showed that utilization of ceramic powder as both binder and aggregate replacement in lime plasters has not just economic and environmental advantages but it also positively influences an extensive set of physical parameters. It was proved in this paper that its utilization is possible up to the studied $50 \%$ of powder raw materials.

\section{Acknowledgement}

This research has been supported by the Ministry of Industry and Trade of the Czech Republic, under project No FR-TI4/014.

\section{References}

[1] Pereira de Oliveira, L.A., Castro-Gomes, J.P., Santos, P.M.S., The potential pozzolanic activity of glass and red-clay ceramic waste as cement mortars components. Construction and Building Materials, 31, pp. 197-203, 2012

[2] Baronio G., Binda L., Study of the pozzolanicity of some bricks and clays. Construction and Building Materials, 11, pp. 41-46, 1997

[3] Poon C., Chan D., The use of recycled aggregate in concrete in Hong Kong, Resources, Conservation and Recycling, 50 (3), pp. 293-305, 2007

[4] Debieb F., Kenai S., The use of coarse and fine crushed bricks as aggregate in concrete. Construction and Building Materials, 22 (5), pp. 886-893, 2008

[5] Pacheco-Torgal, F., Jalali, S., Compressive strength and durability properties of ceramic wastes based concrete. Materials and Structures/Materiaux et Constructions, 44 (1), pp. 155-167, 2011

[6] Heidari, A., Tavakoli, D., A study of the mechanical properties of ground ceramic powder concrete incorporating nano-SiO2 particles. Construction and Building Materials, 38, pp. 255-264, 2013

[7] Reiterman P., Holčapek O., Čáchová M., Vogel F., Jogl M., Konvalinka P., Basic and hygric properties of concrete containing fine ceramic powder. Advanced Materials Research, 897, pp. 188-191, 2014 
[8] Gonçalves J.P., Taveres L.M., Filho T., Fairbairn E., Performance evaluation of cement mortars modified with metakaolin or ground brick. Construction and Building Materials, 23 (5), pp. 1971-1979, 2009

[9] Yan, C.Y., Li, Z.H., Deng, X.M., Experimental study on preparing ecological building mortar by using solid waste. Advanced Materials Research, 763, pp. 199-202, 2013

[10] O'Farrell M., Sabir B.B., Wild S., Strength and chemical resistance of mortars containing brick manufacturing clays subjected to different treatments. Cement and Concrete Composites, 28 (9), 790-799, 2006

[11] Ugurlu E., Boke H., The use of brick-lime plasters and their relevance to climatic conditions of historic bath buildings. Construction and Building Materials, 23 (6), pp. 2442-2450, 2009

[12] Isikdag B., Topcu I.B., The effect of ground granulated blast-furnace slag on properties of Horasan mortar. Construction and Building Materials, 40, pp. 448-454, 2013

[13] Isikdag B., Topcu I.B., Improvement of Khorasan mortar with fly ash for restoration of historical buildings. Science and Engineering of Composite Materials, 21 (3), pp. 359-367, 2014

[14] Čáchová M., Vejmelková E., Koňáková D., Keppert M., Černý R., Influence of finely ground brick on hydric properties of lime plasters. 4th European Conference of Mechanical Engineering, WSEAS Press, Paris, France, pp. 117-121, 2013

[15] Čáchová, M., Koňáková, D., Vejmelkokvá, E., Keppert, M., Reiterman, P., Černý, R., The properties of innovated mortars utilizing secondary raw material. International Conference on High Performance and Optimum Design of Structures and Materials, WIT Press, Ostend, Belgium, 137, pp. 49-56, 2014

[16] Roels S., Carmeliet J., Hens H., Adan O., Brocken H., Černý R., Pavlík Z., Hall C., Kumaran K., Pel L., Plagge R., Interlaboratory Comparison of Hygric Properties of Porous Building Materials. Journal of Thermal Envelope and Building Science, 27 (4), pp. 307-325, 2004

[17] ČSN EN 1015-11 (722400): Methods of test for mortar for masonry - Part 11: Determination of flexural and compressive strength of hardened mortar, 2000

[18] Vejmelková, E., Pavlíková, M., Jerman, M., Černý, R., Free Water Intake as Means of Material Characterization. Journal of Building Physics, 33 (1), pp. 29-44, 2009

[19] Kumaran, M. K., Moisture Diffusivity of Building Materials from Water Absorption Measurements. Journal of Thermal Envelope and Building Science, 22, pp. 349-355, 1999

[20] Applied Precision - ISOMET. (User manual), Bratislava, 1999

[21] R. Černý, P. Rovnaníková: Transport processes in concrete; Spon Press, London 2002 